\title{
Metodologias Ativas no Ensino de Matemática: panorama de pesquisas desenvolvidas em mestrados profissionais
}

\section{Active Methodologies in Math Teaching: overview of research developed in professional masters}

\author{
Guilherme Oliveira de Souza ${ }^{1}$ \\ Douglas da Silva Tinti ${ }^{2}$
}

\section{Resumo}

O presente artigo tem por objetivo apresentar o mapeamento de pesquisas desenvolvidas em Mestrados Profissionais, que investigaram o uso de Metodologias Ativas nos processos de ensino e de aprendizagem da Matemática. Tal mapeamento foi estruturado na perspectiva apresentada por de Fiorentini et al. (2016) e considerou pesquisas disponibilizadas no Banco de Dissertações e Teses da CAPES; usando o descritor "Metodologias Ativas" e o filtro Mestrado Profissional. Considerando estes critérios foram identificadas 242 pesquisas, das quais 240 abordavam Metodologias Ativas. Ao segmentarmos estas pesquisas por área, verificou-se que apenas 16 estudos $(6,67 \%)$ refletiram sobre a utilização destas metodologias nas aulas de matemática. Para a análise destas pesquisas foi realizada uma categorização, de acordo com a Metodologia Ativa considerada no contexto dos estudos analisados. Os dados analisados indicam uma pluralidade de estratégias, públicos e conceitos matemáticos envolvidos na implementação de Metodologias Ativas atrelada às pesquisas desenvolvidas no âmbito dos Mestrados Profissionais.

Palavras-chave: Metodologias Ativa. Mestrados Profissionais. Ensino de Matemática.

\begin{abstract}
This article aims to present the mapping of researches developed in Professional Masters, which investigated the use of Active Methodologies in the teaching and learning processes of Mathematics. This mapping was structured in the perspective presented by Fiorentini et al. (2016) and considered researches made available in the Bank of Dissertations and Theses of CAPES, using the descriptor "Active Methodologies" and the Professional Master filter. Considering these criteria, 242 studies were identified, of which 240 addressed Active Methodologies. The segmentation of these surveys by area, resulted in only 16 studies $(6.67 \%)$ reflecting the use of these methodologies in mathematics classes. For the analysis of these researches a categorization was carried out, according to the Active Methodology considered in the context of the analyzed studies. The analyzed data indicate a plurality of strategies, audiences and mathematical concepts involved in the implementation of Active Methodologies linked to the researches developed within the scope of the Professional Masters.
\end{abstract}

Key words: Active Methodologies. Professional Masters. Math Teaching.

\footnotetext{
${ }^{1}$ Licenciando em Matemática pela Universidade Federal de Ouro Preto - guisouza.math@gmail.com

2 Docente do Departamento de Educação Matemática (DEEMA) da Universidade Federal de Ouro Preto tinti@ufop.edu.br
}

Tangram - Revista de Educação Matemática, Dourados - MS - v.3 n.1, pp. 74-97 (2019) 


\section{Introdução}

Podemos entender Metodologias Ativas como as diferentes estratégias que o docente possui para desenvolver o processo de aprendizagem, de forma interligada, flexível e híbrida, em virtude de uma formação crítica e qualificada perante seus alunos, sendo eles os protagonistas de suas aprendizagens.

Vale ressaltar que essa ênfase na palavra ativa precisa sempre estar associada à aprendizagem reflexiva, para tornar visíveis os processos, os conhecimentos e as competências do que estamos aprendendo com cada atividade (Moran, 2018, p. 3).

É importante destacar a aprendizagem híbrida que viabiliza flexibilidade, mistura e compartilhamento de espaços, tempos, atividades, materiais, técnicas e tecnologias que compõem esse processo ativo.

os modelos de Rotação por Estações, Laboratório Rotacional e Sala de Aula Invertida seguem o modelo de inovações híbridas sustentadas. Eles incorporam as principais características tanto da sala de aula tradicional quanto do ensino on-line. Os modelos Flex, A La Carte, Virtual Enriquecido e de Rotação Individual, entretanto, estão se desenvolvendo de modo mais disruptivo em relação ao sistema tradicional. (Christensen; Horn; Staker, 2013, p. 3)

Nesse sentido, as Metodologias Ativas geram situações de aprendizagem em que os alunos constroem conhecimentos, fundamentam seus pensamentos e tomam decisões sobre os conteúdos que estão sendo abordados. Além disso, potencializam no aluno o processo de autonomia, aptidão em resolver problemas, senso crítico, empatia, responsabilidade, confiança, participação, além do seu protagonismo.

De acordo com Gaeta (2007) o uso de metodologias ativas, pelo fato de romper com a estrutura de disciplinas isoladas e a formação fragmentada do aluno, cria uma dinâmica diferente de aprendizagem, para a qual o professor precisa estar capacitado.

Diante disso, a necessidade de repensarmos espaços de formação docente é inevitável, pois para a utilização desse método de aprendizagem, é fundamental que o professor se aproprie de estratégias e técnicas de ensino que permitem seu público alvo alcançar o objetivo proposto para a aula e, além do mais, que ele participe ativamente do processo de construção do conhecimento. Nesse sentido, a mediação e a interação são os pressupostos essenciais para que ocorra uma aprendizagem significativa (Ausubel, 1982). Tangram - Revista de Educação Matemática, Dourados - MS - v.3 n.1, pp. 74 - 97 (2020) 
Aprendemos, desde que nascemos a partir de situações concretas e, pouco a pouco, conseguimos ampliar e generalizar - processo indutivo - e aprendemos também a partir de ideias ou teorias testá-las depois no concreto - processo dedutivo - (Moran, 2018, p. 2). Logo, o uso das metodologias ativas, se apresenta como uma possibilidade de trabalho com os alunos, que pode potencializar, cada vez mais, tais processos.

A título de exemplificação, cabe ressaltar que, as Metodologias Ativas têm sido implementadas por meio de diversas estratégias, tais como a Aprendizagem Baseada em Projetos (Product-Based Learning), o Ensino Híbrido, os Jogos, a Sala de Aula Invertida, a Instrução por Pares (Peer Instruction), a Aprendizagem Baseada em Times (Team Based Learning), o uso de Tecnologias Educacionais, dentre outras.

Nesse contexto, compreendemos que a relevância deste artigo se justifica pela oportunidade de trazer à tona um panorama das investigações realizadas acerca das Metodologias Ativas no Brasil além de favorecer a ampliação de teorizações acerca da temática, que tem sido apontado como um tema emergente de investigação (Morán, 2015).

\section{Percurso Metodológico}

Como destacado anteriormente, o presente texto é um recorte de uma pesquisa de iniciação científica, que teve por objetivo apresentar o mapeamento de pesquisas desenvolvidas em Metrados Profissionais, que investigaram o uso de Metodologias Ativas nos processos de ensino e de aprendizagem da Matemática.

Para compor o mapeamento, consideramos o Banco de Dissertações e Teses da CAPES, o descritor "Metodologias Ativas" e a perspectiva de Fiorentini et al. (2016, p. 18), que indicam que um mapeamento é:

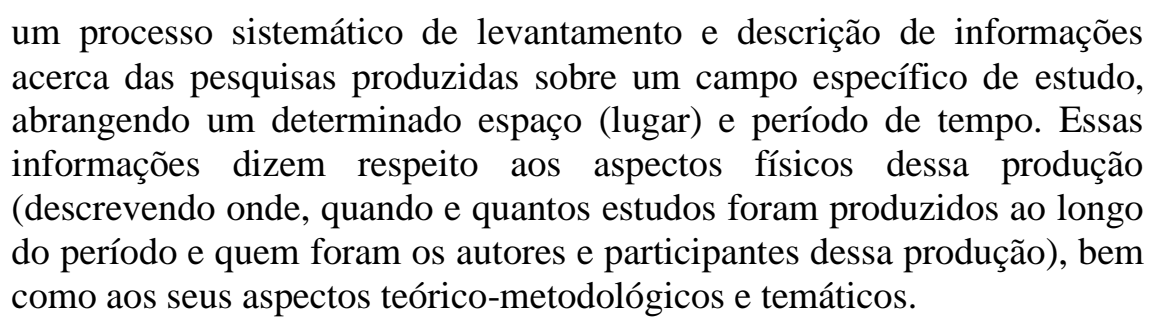

Desse modo, para atingirmos o objetivo da pesquisa, estabelecemos as seguintes etapas:

a) Etapa 1: levantamento de dados

Tangram - Revista de Educação Matemática, Dourados - MS - v.3 n.1, pp. 74 - 97 (2020) 
Metodologias Ativas no Ensino de Matemática: panorama de pesquisas desenvolvidas em mestrados profissionais

Ao realizarmos um mapeamento, a priori, no Banco de Dissertações e Teses da Coordenação de Aperfeiçoamento de Pessoal de Nível Superior (CAPES) ${ }^{3}$, considerando o descritor "Metodologias Ativas" bem como o filtro de Teses e Dissertações de Mestrado Acadêmico e Profissional, foram identificados 563 estudos realizados no período de 2004 a $2018^{4}$, como demostramos na Tabela a seguir.

Tabela 1: Pesquisas que consideraram o descritor "Metodologias Ativas" segmentadas por nível de estudo.

\begin{tabular}{|c|c|c|}
\hline Nível & Total & \% \\
\hline Mestrado Profissional & 242 & 42,98 \\
\hline Mestrado Acadêmico & 216 & 38,37 \\
\hline Doutorado & 105 & 18,65 \\
\hline Total & $\mathbf{5 6 3}$ & $\mathbf{1 0 0}$ \\
\hline
\end{tabular}

Fonte: produzidos pelos autores a partir de consulta realizada no banco de Dissertações e

Teses da CAPES (2019).

Se considerarmos o ano de conclusão dessas pesquisas, perceberemos um crescimento das investigações acerca da temática das Metodologias Ativas, ao longo dos anos e em todos os níveis de estudo, como evidenciamos na Tabela 2, tendo a produção de 2017 um crescimento expressivo (72,22\%) em relação a produção do ano de 2016.

${ }^{3}$ Disponível em: http://catalogodeteses.capes.gov.br/catalogo-teses/\#!/

${ }^{4}$ Atualizado em 19 de fevereiro de 2019.

Tangram - Revista de Educação Matemática, Dourados - MS - v.3 n.1, pp. 74 - 97 (2020) 
Metodologias Ativas no Ensino de Matemática: panorama de pesquisas desenvolvidas em mestrados profissionais

Tabela 2: Pesquisas que consideraram o descritor "Metodologias Ativas" segmentadas por nível de estudo e ano.

\begin{tabular}{|c|c|c|c|c|}
\hline Ano de defesa & $\begin{array}{c}\text { Mestrado } \\
\text { Profissional }\end{array}$ & Mestrado & Doutorado & Total \\
\hline 2004 & 0 & 2 & 0 & 2 \\
\hline 2005 & 0 & 0 & 0 & 0 \\
\hline 2006 & 0 & 1 & 1 & 2 \\
\hline 2007 & 0 & 2 & 2 & 4 \\
\hline 2008 & 0 & 1 & 2 & 3 \\
\hline 2009 & 0 & 4 & 1 & 5 \\
\hline 2010 & 0 & 4 & 1 & 5 \\
\hline 2011 & 0 & 7 & 5 & 12 \\
\hline 2012 & 0 & 11 & 2 & 13 \\
\hline 2013 & 11 & 10 & 11 & 32 \\
\hline 2014 & 26 & 9 & 9 & 44 \\
\hline 2015 & 37 & 23 & 14 & 74 \\
\hline 2016 & 43 & 26 & 7 & 72 \\
\hline 2017 & 51 & 55 & 19 & 124 \\
\hline 2018 & 74 & 61 & 31 & 166 \\
\hline Total & $\mathbf{2 4 2}$ & $\mathbf{2 1 6}$ & $\mathbf{1 0 5}$ & $\mathbf{5 6 3}$ \\
\hline
\end{tabular}

Fonte: produzidos pelos autores a partir de consulta realizada no banco de Dissertações e

Teses da CAPES (2019).

b) Etapa 2: organização e tratamento dos dados

Iniciamos a organização dos dados pelas pesquisas vinculadas a Mestrados Profissionais. Desse modo, ao analisarmos as 242 dissertações, identificamos que 2 delas não possuem relação com Metodologias Ativas. Segmentamos, então, as 240 dissertações de Mestrado Profissional por áreas do conhecimento, conforme apresentamos na Tabela 3.

Tabela 3: Pesquisas de Mestrados Profissionais sobre Metodologias Ativas segmentadas por áreas de conhecimento.

\begin{tabular}{|c|c|c|}
\hline Área & Total & \% \\
\hline Saúde & 154 & 64,17 \\
\hline Educação & 21 & 8,75 \\
\hline Matemática & 16 & 6,67 \\
\hline Física & 12 & 5,00 \\
\hline Tecnologia & 8 & 3,33 \\
\hline Ciências & 3 & 1,25 \\
\hline Engenharia & 3 & 1,25 \\
\hline Outras & 23 & 9,58 \\
\hline Total & $\mathbf{2 4 0}$ & $\mathbf{1 0 0}$ \\
\hline
\end{tabular}

Fonte: produzidos pelos autores (2019).

Tangram - Revista de Educação Matemática, Dourados - MS - v.3 n.1, pp. 74 - 97 (2020) 
Metodologias Ativas no Ensino de Matemática: panorama de pesquisas desenvolvidas em mestrados profissionais

Para apresentarmos o panorama das tendências temáticas das pesquisas sobre Metodologias Ativas no âmbito dos Mestrados Profissionais, foram estabelecidas categorias a partir da(s) Metodologia(s) Ativa(s) focalizada no estudo analisado.

Tabela 4: Focos de análise e pesquisas relacionadas

\begin{tabular}{|c|c|}
\hline Focos & Pesquisas \\
\hline Aprendizagem Baseada em Projetos & Santos (2018) \\
\hline Ensino Híbrido & Schmitt (2018) \\
\hline Jogos & Silva (2017); Santos (2018) \\
\hline Sala de Aula Invertida & Almeida (2017); Matos (2018); \\
& Moreira (2018) \\
\hline Instrução por Pares (Peer Instruction) & Paiva (2016); Passos (2016); Silva \\
\hline Peer Instruction e Aprendizagem Baseada em & (2016); Gomes (2018) \\
Times (Team Based Learning) & Oliveira (2015); Queiroz (2018); \\
\hline & Sanches (2018); Souza (2018) \\
\hline Uso de Tecnologia educacional & \\
\hline
\end{tabular}

Fonte: produzidos pelos autores (2019).

A seguir, as pesquisas são apresentadas, dentro de cada categoria, destacando os seus objetivos, qual o tipo de pesquisa, as atividades propostas para o público alvo, o desenvolvimento do planejamento, os principais resultados e as conclusões.

\section{Análise de Dados}

\section{Pesquisas que focalizaram a Aprendizagem Baseada em Projetos}

A pesquisa desenvolvida por Santos (2018) retrata um estudo voltado para alunos do Ensino Médio, utilizando como recurso didático, a metodologia ativa intitulada Aprendizagem Baseada em Projetos (ABPj).

A autora relata que, inicialmente, realizou pesquisas em livros, artigos, dissertações e revistas científicas na internet para conhecimento e exploração do tema $\mathrm{ABPj}$ para o desenvolvimento dessa metodologia ativa dentro de uma sala de aula.

Tangram - Revista de Educação Matemática, Dourados - MS - v.3 n.1, pp. 74 - 97 (2020) 
Trata-se de uma pesquisa ação, que foi realizada em dois ciclos. O primeiro ciclo foi feito em uma turma de 25 alunos de matemática do $1^{\circ}$ ano do Ensino Médio, com duração de setembro a dezembro de 2015. Nesse ciclo, as atividades envolviam conhecimentos sobre Geometria e foram divididas em 5 partes: projeto de pesquisa, planta baixa, apresentação da planta baixa, desenvolvimento do projeto e o produto.

E o segundo ciclo foi desenvolvido em 3 turmas do Ensino Médio, no período de fevereiro a agosto de 2017, e foi dividido em 13 etapas: apresentação do projeto, definição do problema, apresentação do roteiro do projeto de pesquisa, feedback do projeto de pesquisa, apresentação do relatório, aplicação do questionário, apresentação final do projeto e uma auto avaliação.

Para a coleta de dados, Santos (2018) utilizou questionários, fotografias e as produções dos alunos e, essa coleta, partiu-se devido à observação dos baixos resultados de avaliações dos alunos, onde, no ano de 2015 , apenas 33,3\% dos alunos que cursaram o $1^{\circ}$ ano do Ensino Médio foram aprovados. A pesquisadora, por meio da tabulação e descrição, analisou os dados obtidos durante os dois ciclos de pesquisa.

Santos (2018) conclui que a ABPj se mostrou capaz de orientar o processo de aprendizagem como um método de ensino dinâmico ao propiciar o desenvolvimento de aulas diferenciadas que motivaram a aprendizagem para a resolução de problemas, um dos grandes obstáculos enfrentados atualmente na disciplina. Os alunos participantes assumiram o papel de pesquisadores e passaram a ter a oportunidade de tornarem-se protagonistas de tal aprendizagem na busca por soluções dos problemas. Os estudantes apresentaram aprimoramento a capacidade de aprender, exploraram a criatividade e permitiu a aquisição do conhecimento a partir da realização de atividades práticas.

\section{Pesquisas que focalizaram o Ensino Híbrido}

O público alvo do estudo de Schmitt (2018) foi alunos do $2^{\circ}$ ano e do $6^{\circ}$ ano do Ensino Fundamental. Utilizou-se, como recurso didático, a metodologia intitulada Ensino Híbrido.

A pesquisa teve início, em consenso com a direção da escola, em duas frentes: com a turma do $2^{\circ}$ ano e com a turma do $6^{\circ}$, na qual era a turma que a pesquisadora lecionava. As duas turmas estudavam em tempo integral, na qual é um período em que os alunos fazem

Tangram - Revista de Educação Matemática, Dourados - MS - v.3 n.1, pp. 74 - 97 (2020) 
tarefas de casa e estudo assistido, havendo um maior tempo para a experimentação do que no período não-integral.

Uma série de aplicativos educativos, de várias áreas do conhecimento (Matemática, Português, Ciências, etc.) foram testados com a turma do $6^{\circ}$ ano, usando da ferramenta do Google Classroom para registrar a percepção dos alunos e evolução pessoal em cada atividade proposta, permitindo um feedback instantâneo ao professor.

Para a pesquisa com a turma do $2^{\circ}$ ano, o trabalho começou com o uso de tablets para a implementação de jogos educativos. A ideia por trás do uso dos tablets deve-se ao fato deles serem touchscreen, com fácil manuseio para a realização das tarefas propostas e por uma imaturidade da turma para o uso de notebooks. Além do mais, para a pesquisadora, eram um público perfeito para o desenvolvimento de autonomia e também testar o impacto da tecnologia no estudo. Assim como a turma do $6^{\circ}$ ano, o Google Classroom foi utilizado para a turma do $2^{\circ}$ ano, compartilhando todas as tarefas feitas dentro de sala em uma rede social.

Schmitt (2018) conclui que o experimento de trazer Gamificação produtiva para essa faixa etária foi um absoluto sucesso, pois para as crianças os jogos educativos postados como tarefa do Classroom não eram vistos como estudo, mas como divertimento, logo, o engajamento foi total. Percebeu-se que os alunos do $2^{\circ}$ ano do Ensino Fundamental tiveram um pouco mais de dificuldade no início para entenderem o procedimento de fazer login em sua conta para acessar a plataforma, mas quando foi entendida uma vez, não tiveram mais dificuldades e ficaram confortáveis com a utilização dos tablets. Verificou-se também, que as capacitações foram bem-sucedidas, além do uso do recurso tecnológico em si, sendo necessário contextualizar a aplicação da ferramenta ás necessidades dos docentes e dos alunos.

\section{Pesquisas que focalizaram a utilização de Jogos}

A pesquisa de Santos (2018) focalizou alunos do Ensino Técnico, utilizando como recurso didático, a metodologia intitulada Jogos. O objetivo do estudo foi possibilitar que os alunos dos primeiros anos do Ensino Técnico Integrados ao Ensino Médio em Edificações, Informática e Química pudessem, além de reforçar os assuntos abordados, (que são função exponencial e logarítmica), conhecer técnicas distintas da resolução dos problemas propostos à turma.

Tangram - Revista de Educação Matemática, Dourados - MS - v.3 n.1, pp. 74 - 97 (2020) 
A coleta de dados foi realizada em uma turma com 90 alunos, em 5 aulas, com duração de 50 minutos cada. O jogo utilizado pelo pesquisador foi o Summaê, ferramenta na qual utilizam perguntas e respostas elaboradas pelos próprios alunos envolvidos na atividade.

Santos (2018) conclui que, além de reforçar os assuntos abordados em sala de aula, permita que o aluno reflita e descubra aplicações práticas, pois na elaboração de problemas naturalmente a praticidade dentro da abordagem do tema ficará mais ampla, além de uma socialização dos alunos, com a criação de duplas ou até mesmo trios, que deverão interagir entre si. A aplicação da metodologia resultou em respostas positivas quanto ao que foi tratado, gerando um grande interesse e comprometimento da turma com o que estava sendo proposto.

Já Silva (2017) retrata um estudo voltado para alunos dos anos finais do Ensino Fundamental, utilizando como recurso didático, a metodologia intitulada jogos.

A problematização da pesquisa tem como pressuposto a ideia de que os jogos matemáticos, que no caso foi utilizado o "Joga Monte" pode auxiliar na aprendizagem e assim constitui-se num recurso pedagógico interessante e efetivo no ensino de números inteiros. Outro fator de destaque é a interação social, o uso da linguagem como meio de aprendizagem e ações colaborativas que o jogo proporciona ao ser implementado.

O objetivo da pesquisa foi analisar o processo de ensino aprendizagem e avaliar a eficiência de um jogo matemático como recurso de intervenção pedagógica, em relação ao conteúdo dos números relativos e em três cenários distintos do Ensino Fundamental, com os $5^{\circ}, 7^{\circ}$ e $8^{\circ}$ anos.

Trata-se de uma pesquisa ação, foi dividido em 4 etapas: Pré-teste, pré-conhecimento dos alunos sobre números relativos, nível inicial de seus conhecimentos sobre o tema e por fim o Pós-teste.

$\mathrm{Na}$ fase de pré-teste, foram feitas perguntas para ter o conhecimento se os alunos tinham contato com algum tipo de jogo, e nos três cenários a grande maioria dos alunos disseram que jogavam os 2 jogos, que no caso, eram jogos de cartas e tabuleiros e que na opinião dos alunos, os jogos ajudavam muito no seu processo de aprendizagem. A maioria dos alunos do cenário 1 e 2 não viam aplicação dos números inteiros em seu dia a dia, já no cenário 3, a turma dividiu-se quando a essa pergunta.

Tangram - Revista de Educação Matemática, Dourados - MS - v.3 n.1, pp. 74 - 97 (2020) 
No pós-teste, fazendo uma comparação com as perguntas praticadas no início do projeto com as perguntas aplicadas ao final, nos três cenários, houve um grande aumento no número de acertos das respostas dos alunos.

Silva (2017) conclui que o jogo efetivamente faz parte do cotidiano dos alunos, com faixa etária de 10 a 14 anos. De forma positiva, verificou-se que existe uma percepção, vinda dos próprios alunos, de que os jogos auxiliam no processo de ensino aprendizagem. Observou-se uma dificuldade dos alunos com a existência de um número menor do que zero e com a distância entre um valor positivo e um negativo. Por fim, a pesquisadora conclui que o jogo "Compra Monte" favorece a aprendizagem dos números inteiros negativos, tanto no ano adequado como também que tal assunto possa ser discutido em anos anteriores, desde que siga um planejamento e que sofra adaptações necessárias.

\section{Pesquisas que focalizaram a utilização de Sala de Aula Invertida}

A pesquisa realizada por Moreira (2018) demonstra um estudo voltado para alunos do Ensino Superior, utilizando como recurso didático, a metodologia intitulada, Sala de Aula Invertida.

Este trabalho tem como objetivo discutir as características do ensino da matemática, as mudanças que ocorreram ao longo do tempo, influenciadas pela evolução da tecnologia, analisando as Metodologias Ativas relacionadas a matemática, destacando aquelas que se utilizam de ferramentas tecnológicas em sua prática pedagógica e destacando a metodologia da Sala de Aula Invertida.

Realizou-se uma pesquisa, com o intuito de aprofundamento dos conhecimentos, conceitos e das características da metodologia em destaque, com um grupo de 105 estudantes (porém apenas 52 alunos foram as aulas) do $1^{\circ}$ período de vários cursos, matriculados no Curso de Nivelamento/2018, com carga horária de 30 horas semanais.

A este grupo, foi destinado a metodologia Sala Invertida, em um contexto de ensino híbrido, com aulas presenciais e materiais disponibilizados, como vídeo aulas, textos teóricos, exemplos, questionários e atividades, na plataforma Moodle.

Moreira (2018) conclui que foi notório algumas características positivas, como o envolvimento da turma com as atividades propostas, detectou uma melhora no nível de conhecimento dos alunos com avaliação anteriores e posteriores ao trabalho realizado,

Tangram - Revista de Educação Matemática, Dourados - MS - v.3 n.1, pp. 74 - 97 (2020) 
souberam lidar muito bem com a metodologia utilizada, tirando excelentes notas durante o processo das aulas. Concluiu também um aprimoramento na autonomia dos alunos e uma personificação, do tempo estipulado para cada atividade, em relação a prazos e o que era desejado pela questão.

Já o estudo de Almeida (2017) foi realizado alunos dos anos finais do Ensino Fundamental, utilizando, também, a Sala de Aula Invertida.

A aplicação da proposta de desigualdades e inequações, foram aplicadas em duas turmas do $8^{\circ}$ ano e teve duração de 5 horas/aulas durante 4 semanas. Almeida (2017) sinaliza que a pesquisa foi dividida em 5 etapas: motivação, material online, resolução e apresentação das tarefas, resolução dos desafios e, por último, diversificação das tarefas.

Na primeira etapa, motivação, teve como propósito fazer com que o aluno se envolva nas atividades propostas e adquirir conhecimentos iniciais relacionados com os conteúdos que serão estudados e, para isso, foram criados atividades e questionários. Na parte do material online, o objetivo foi que os alunos, por meio de vídeo aulas, possam, assim como na etapa anterior, aderir um conhecimento prévio dos assuntos a serem abordados no decorrer das aulas. Para a execução da terceira etapa, os alunos, após separados em grupos, receberam alguns exercícios e problemas do próprio material didático para que fossem resolvidos, apresentados e explicados aos demais colegas. Na quarta etapa, os alunos resolveram desafios em período extraclasse e também em aula, apresentaram e detalharam os caminhos que eles utilizaram para chegar na conclusão. Na última etapa, os alunos se depararam com questões variadas, que pudessem explorar aspectos de conteúdos ainda não destacados.

Almeida (2017) destaca que o estudo da elaboração da Proposta de Aplicação da Sala de Aula Invertida (PASAI), teve uma grande importância para a realização da pesquisa e conclui que as questões poderiam ter acrescentado mais qualidade ao processo da pesquisa, entre elas, a melhor divulgação e informação aos pais dos alunos da turma do $8^{\circ}$ ano, sobre a metodologia utilizada, pois seria essencial para um melhor desenvolvimento dos alunos. Foi notório a participação maciça dos alunos quanto ao que foi proposto, o que ocasionou em uma melhor compreensão dos alunos em relação ao tema tratado, mas houve, em contrapartida, uma dificuldade quanto aos materiais que eram disponibilizados de forma online.

Tangram - Revista de Educação Matemática, Dourados - MS - v.3 n.1, pp. 74 - 97 (2020) 
Matos (2018) desenvolveu um estudo com alunos dos anos finais do Ensino Fundamental, utilizando a Sala de Aula Invertida. O objetivo foi desenvolver e analisar a aplicação de um modelo didático cíclico, contendo 7 etapas, com objetivos específicos. Além de fazer uso da metodologia no ensino da matemática, mediada por tecnologias, com estudantes dos anos finais do Ensino Fundamental.

As etapas do projeto foram: problema motivador, vídeo aula, avaliação diagnóstica, formação de grupos, atividade, debate da turma e avaliação da aprendizagem.

A proposta para a primeira etapa da pesquisa é instigar os alunos a pensarem em um problema, devendo fazer parte do contexto do tema para servir de estudo para os demais colegas. Na etapa dois, as vídeo-aulas, que foram gravadas pelo próprio pesquisador, devese ao fato de ser um mecanismo digital de fácil acesso e com um apelo mais atrativo para os alunos. Na terceira etapa, a avaliação foi feita de forma individual e sem consulta, contendo 15 questões de múltipla escolha, tendo como objetivo diagnosticar quais alunos já possuíam os conhecimentos básicos necessários. Para a etapa quatro, foram formados grupos heterogêneos, com alunos de diferentes níveis de aprendizado, fazendo com que os grupos trabalhassem de forma coletiva para que todos conseguissem atingir a solução problema. Já na quinta etapa, os alunos, dentro de cada grupo tiveram a oportunidade de trocar experiências e ideias entre si, estimulando os que possuíam mais facilidade com o assunto a ajudarem os que apresentavam mais dificuldades. Na próxima etapa, com o objetivo de achar um denominador comum nas soluções propostas por cada aluno, o debate pode ocorrer tanto entre os próprios grupos quanto com a sala toda, tendo em vistas que os integrantes dos grupos já se comunicavam bastante entre eles. Na última etapa, por meio da ferramenta Google Formulários, foram feitas avaliações para os alunos, de forma que o resultado demonstrava o real conhecimento de cada um sobre as atividades que foram propostas.

Matos (2017) conclui que a Aprendizagem Baseada em Problemas aumentou o interesse por parte dos estudantes, antes da exposição do conteúdo. A Aprendizagem Baseada em Equipes ajudou a disseminar as diferenças no aprendizado da classe, com significativo destaque na melhora dos alunos que possuíam mais dificuldades, dando a oportunidade de o professor demandar uma atenção pontual e assertiva aos que mais necessitavam. A comparação dos resultados entre avaliações diagnósticas e avaliações de 
Metodologias Ativas no Ensino de Matemática: panorama de pesquisas desenvolvidas em mestrados profissionais

aprendizagem permitiu analisar os efeitos positivos da Sala de Aula Invertida em Matemática (SAIMAT), na aprendizagem dos alunos.

\section{Pesquisas que focalizaram a utilização da Instrução por Pares (Peer Instruction)}

As pesquisas realizadas por Passos (2016) e Silva (2016) trazem uma mesma perspectiva na qual retratam um estudo voltado para alunos do Ensino Médio, utilizando como recurso didático, a metodologia intitulada Tecnologia Educacional. Apesar das pesquisas sinalizarem que utilizaram Tecnologias Educacionais, especificamente a ferramenta Socrative, optamos por inseri-las nesta categoria por entendermos que o uso deste software se enquadra na perspectiva da Peer Instruction.

O trabalho foi elaborado para servir de orientação aos professores que desejam utilizar em suas aulas Metodologias Ativas no ensino de funções quadráticas utilizando recursos de avaliação instantâneas verificadas por meio do software Socrative.

O trabalho proposto tratou-se de uma aula na qual foram aplicadas Metodologias Ativas com auxílio do software Socrative. O mesmo foi realizado com os alunos que já estudaram o conteúdo, servindo assim, como uma complementação, aprofundamento e uma forma alternativa para diagnosticar e reparar possíveis déficits no aprendizado de Função Quadrática, utilizando como recursos a tecnologia e o trabalho em grupo.

Primeiramente, foi passado uma situação problema para os grupos e em seguida foram distribuídas 6 atividades para eles, tratando sobre a situação problema, para discutirem entre si e depois as resolverem.

Ao responderem as questões por meio do Socrative, o programa gerou dois tipos de relatórios: Um relatório geral e outro individual por grupo. O relatório geral ordena todas as atividades e as respostas, já relacionando os acertos e os erros totais por atividade. No relatório individual por grupos, constam todas as respostas em cada atividade e o percentual de acertos de cada grupo, facilitando uma avaliação personalizada de cada um deles.

Para Passos (2016) e Silva (2016), a aula experimental possibilitou verificar que a associação entre o software Socrative e uma metodologia ativa de ensino. O uso das Metodologias Ativas em sala de aula mostrou ser uma excelente alternativa para obter a atenção dos alunos e diversificar as possibilidades de abordagem de um conteúdo durante as aulas. Sendo bem aplicadas, faz com que os alunos aprendam mais do que técnicas de

Tangram - Revista de Educação Matemática, Dourados - MS - v.3 n.1, pp. 74 - 97 (2020) 
resolver problemas matemáticos. Eles aprendem a argumentar para defender os seus pontos de vista e aos poucos vão se tornando cidadãos críticos.

A pesquisa realizada por Gomes (2018) retrata um estudo voltado para alunos do Ensino Médio, utilizando como recurso didático, a metodologia intitulada Peer Instruction.

O autor teve como objetivo apresentar uma proposta de ensino associada ao uso de Metodologias Ativas com auxílio de tecnologias educacionais, nesse caso, o software Socrative, diante de um conteúdo da matemática, a saber, Polinômios.

A implementação da metodologia foi dividida em 3 momentos: explanação do conteúdo, aplicação da primeira avaliação usando o Socrative e aplicação do "Jogo da Nave".

No primeiro momento, foram passados exercícios para os alunos resolverem para que houvesse uma melhor compreensão do conteúdo proposto e em seguida foi elaborado um questionário, contendo 5 questões, disponibilizada em sala de aula, por meio do Socrative, com o intuito dos estudantes irem se familiarizando com a ferramenta. No momento dois, houve a aplicação de uma avaliação sobre polinômios que estava no Socrative Student, contendo 30 minutos para a sua realização. No último momento, a aplicação do "Jogo da Nave", que está presente no Socrative, foi aplica em 2 horas/aulas, com grupos de 4 ou 5 pessoas, sendo que cada grupo teria que possuir um smartphone para acesso à internet.

Após o término da avaliação foram analisados os relatórios gerados pelo Socrative, onde era possível verificar as questões acertadas por cada um dos grupos. Em seguida, aos grupos que não conseguiram responder ao questionário de forma correta, foi solicitado ao grupo para exporem suas dúvidas, para que as mesmas fossem sanadas pelos seus colegas.

Gomes (2018) conclui que, durante a aplicação da metodologia, pôde-se observar que os alunos se mostraram mais motivados e engajados com o uso da aprendizagem pelos colegas em relação às aulas anteriores. $\mathrm{O}$ fato de poderem realizar as avaliações utilizando o Socrative, por meio do smartphone em sala de aula, causou um grande entusiasmo entre os alunos, pois foi possível obter de forma imediata um controle sobre o desempenho dos alunos em relação ao conteúdo abordado em sala, para que pudesse fazer uma intervenção de forma direta diante do que não foi compreendido.

Tangram - Revista de Educação Matemática, Dourados - MS - v.3 n.1, pp. 74 - 97 (2020) 
O trabalho de Sanches (2018) apresenta um estudo voltado para alunos do Ensino Médio. Teve como objetivo de servir de orientação aos docentes que desejam utilizar em suas aulas uma aprendizagem dinâmica no ensino de matrizes e sistemas de equações lineares utilizando recursos de avaliação instantâneas verificadas por meio do software Socrative. Assim como as pesquisas de Passos (2016) e Silva (2016), enquadraremos a de Sanches (2018) nesta categorização.

A atividade foi realizada em uma instituição de ensino particular, com 20 alunos da turma do $3^{\circ}$ ano do Ensino Médio, e teve a duração de uma hora e quarenta minutos. Os discentes foram orientados a pesquisar situações problemas que se resolveriam com o auxílio de Matrizes e Sistemas Lineares. Após os estudos, os estudantes foram divididos em quatro grupos de cinco alunos cada, e foi distribuída uma atividade com cinco questões para serem resolvidas pelos grupos. Foram criadas 5 questões para os grupos.

A sala foi organizada em grupos de 5 alunos, conforme planejado. Os grupos foram sorteados no momento pelo professor para possibilitar a interação entre os alunos, que foram colocados em círculos, fato característico em ambientes dinâmicos de aprendizagem. Após a organização do ambiente, as questões foram entregues aos grupos por meio de listas de exercícios.

Aos finalizarem as atividades, todas as questões foram resolvidas no quadro branco por um integrante de cada grupo que foi sorteado aleatoriamente. Quando algum desses representantes apresentavam dificuldades, era permitida uma ajuda por meio de algum componente de seu grupo.

Portanto, a interação dentro dos grupos mostrou-se uma excelente ferramenta em sala de aula, pois as dúvidas menos complexas que surgiam, em grande parte, eram resolvidas pelo próprio grupo valorizando o conhecimento prévio de cada aluno.

Sanches (2018) conclui que, durante o desenvolvimento das atividades, os alunos se mostraram bastante envolvidos com a proposta de aprendizagem, principalmente por se tratar de uma nova forma de se aprender. Com o estudo prévio dos assuntos abordados eles sentiram poucas dificuldades durante a realização das atividades. A proposta de intervenção possibilitou verificar que a associação entre o software Socrative e uma metodologia ativa de ensino, além de dinamizar a sala de aula, permite ao docente tomar decisões guiado pelos resultados das avaliações instantâneas, transformando assim mais dinâmica a mediação no

Tangram - Revista de Educação Matemática, Dourados - MS - v.3 n.1, pp. 74 - 97 (2020) 
andamento das atividades. Além disso, o autor pontua que ao empregar o Socrative e as Metodologias Ativas nas suas aulas, o docente economizará tempo para correção das avaliações, recursos como papel e tinta de impressão que utilizaria para fazer suas atividades. Assim, o professor desenvolverá atividades distintas que tornarão suas aulas mais atrativas para seus alunos do ensino básico que estão cada vez mais resistentes às aulas tradicionais, desconexas das suas realidades e mais interligadas ao avanço tecnológico.

A pesquisa de Paiva (2016) apresentada um estudo voltado para alunos do Ensino Médio, considerando a metodologia intitulada Peer Instruction. Objetivou contribuir com a discussão no âmbito da atuação do professor de matemática. O trabalho apresenta uma breve descrição sobre algumas metodologias de aprendizagem ativas e colaborativas que estão sendo utilizadas em universidades e escolas do Brasil, e de outros países.

O trabalho foi dividido em 2 etapas: proposta de uma aula sobre função afim com o uso da Aprendizagem pelos Colegas (ApC) e a aplicação da ApC em sala de aula.

Na primeira etapa, tendo como finalidade a aplicação do método em salas de aula de uma escola pública, foi escolhido confeccionar um material que pudesse ser impresso em poucas folhas para serem entregues aos alunos uma aula antes da aplicação do método. $\mathrm{O}$ material teórico contém 4 exemplos que representam a ideia de proporcionalidade.

Para a aplicação da ApC em sala de aula, foram confeccionados 35 kits de flashcards, cada kit com as letras A, B, C, D e E, impressas em papel canson, colados em cartolina e cobertos com papel contact para aumentar a durabilidade. A atividade proposta foi feita em uma turma do $1^{\circ}$ contendo 32 alunos.

Paiva (2016) conclui que, após a aplicação de uma aula feita na perspectiva da ApC, foi observado o aumento do interesse dos alunos, muito maior durante as aulas com o uso da aprendizagem pelos colegas em relação às aulas anteriores, tradicionais e totalmente expositivas. Isso provavelmente se deve a dois fatores: às discussões entre os colegas proporcionada, intencionalmente pela metodologia, o que deixa a aula mais dinâmica; e à diminuição da parte teórica da aula, haja visto que grande parte da teoria foi entregue antes para que os alunos estudassem em casa. $\mathrm{O}$ ganho na quantidade de acertos em relação às questões de avaliação apresentadas foi bem expressivo, devido às discussões entre os alunos e à literatura pesquisada.

Tangram - Revista de Educação Matemática, Dourados - MS - v.3 n.1, pp. 74 - 97 (2020) 
Metodologias Ativas no Ensino de Matemática: panorama de pesquisas desenvolvidas em mestrados profissionais

\section{Pesquisas que focalizaram a utilização do Peer Instruction e do Team Based Learning}

Rech (2016) retrata um estudo voltado para a formação iniciada de professores, utilizando como recurso didático, as metodologias intituladas Peer Instruction e Team Based Learning. Trata-se de investigação realizada, a partir de uma intervenção pedagógica, com um grupo de 18 professores que ministravam aulas de Matemática. A pesquisa teve como objetivo verificar como uma formação inicial, de professores que já ministram aulas, com ênfase em Metodologias Ativas de ensino, pode impactar nas práticas pedagógicas dos professores.

Para tanto, utilizou-se de uma pesquisa descritiva, que teve uma coleta de dados estruturada em 4 partes: a realização de um questionário, aplicado antes da intervenção pedagógica, com perguntas abertas, com o objetivo de conhecer as principais dificuldades do ensino da matemática; transcrições de filmagens, depoimentos descritos em diários de campo e uma proposta de ensino e aprendizagem focadas nas duas metodologias (Peer Instruction e Team Based Learning), as quais foram aplicadas pelos participantes do estudo em suas práticas de ensino de Matemática.

Rech (2016) conclui que, na análise de resultados, foi possível verificar que o curso de formação inicial, com ênfase em Metodologias Ativas de ensino, pode contribuir nas práticas pedagógicas dos professores, pois os professores cursistas voltaram a ter a sensação que um aluno tem ao aprender algo novo e interessante, fazendo, com a prática, uma volta ao seu passado acadêmico. Desta forma, desenvolveram as atividades com grande empenho e cooperação, aplicando as Metodologias Ativas concebidas no curso de formação inicial com seus alunos, o que culminou em resultados positivos, percebidos nos depoimentos dos próprios alunos.

\section{Pesquisas que focalizaram a utilização de Tecnologia Educacional}

Queiroz (2018) apresenta um estudo voltado para alunos de todos os anos finais do Ensino Fundamental. Esse estudo teve por objetivo aplicar uma sequência didática sobre polígonos regulares e seus elementos a partir da construção e exploração de figuras poligonais variadas, utilizando o software Scratch.

Tangram - Revista de Educação Matemática, Dourados - MS - v.3 n.1, pp. 74 - 97 (2020) 
Além do mais, teve a intenção de explorar as potencialidades da linguagem de programação Scratch e a possibilidade de integrá-la ao currículo de Matemática, com foco na Geometria. O software Scratch foi apresentado de forma didática, direcionado ao professor que busca inovar suas aulas usando tecnologias eficazes e que despertem o interesse do aluno.

Para cada turma dos anos finais do Ensino Fundamental, foi realizado propostas de sequências didáticas diferentes e os temas escolhidos foram analisados e extraídos da Base Nacional Comum Curricular (Brasil, 2017). Foram propostas diversas atividades, não só utilizando o Scratch, mas também, o uso de materiais concretos, investigativos, projetos em grupos, construções geométricas com instrumentos manuais e softwares auxiliares, como o Geogebra.

Para cada turma, foram propostos os seguintes conteúdos:

- $6^{\circ}$ ano - polígonos regulares, classificação de triângulos quanto aos seus ângulos e seus lados, classificação dos quadriláteros e suas propriedades e fractal: triângulo de Sierpinski.

- $7^{\circ}$ ano - polígonos regulares, condição de existência de um triângulo, classificação de triângulos quanto aos seus ângulos e seus lados e transformações geométricas: reflexão, translação e rotação.

- $8^{\circ}$ ano - classificação dos quadriláteros e suas propriedades; e transformações geométricas: reflexão, translação e rotação.

- $9^{\circ}$ ano - teorema de Pitágoras e fractal: triângulo de Sierpinski.

Queiroz (2018) conclui que, o uso de tecnologias alinhado às estratégias de aprendizagem ativa, possibilitaram aos alunos atrelar significado ao que aprenderam, tornando-se protagonistas na construção de seu conhecimento. Muitas habilidades foram desenvolvidas no quesito de programação, como pensar, organizar, refinar, refletir ou criar, que contribuíram significativamente para o aprendizado num contexto mais amplo.

Já a pesquisa de Oliveira (2015) revela um estudo voltado para a formação continuada de professores. Objetivou compreender as aprendizagens e as estratégias de ensino a partir da mediação pedagógica observadas nas práticas do ambiente virtual de aprendizagem entre professores de uma escola pública. Foram sujeitos dessa pesquisa quatro professores da disciplina de Matemática de uma escola pública estadual.

Tangram - Revista de Educação Matemática, Dourados - MS - v.3 n.1, pp. 74 - 97 (2020) 
Trata-se de uma pesquisa ação, onde o trabalho foi divido em 4 momentos de atuação e de análise: a) foi aplicado um questionário com 17 professores, com o intuito de verificar algumas informações a respeito de suas rotinas, tais como a frequência do uso de computadores fora e dentro da escola; b) Em seguida, foram feitas 7 reuniões para o discurso do planejamento das aulas; c) O próximo passo foi os dados de acesso e a utilização da plataforma Moodle, onde essa parte da pesquisa foi direcionada a realizar uma análise dos professores sobre o acesso e utilização da Plataforma Virtual de Aprendizagem; d) Por último, houve uma análise sobre a atuação dos professores no ambiente virtual de aprendizagem.

Quanto à participação colaborativa dos professores no processo, o autor fez uma análise separando em 7 categorias: (Desistência, Ausência, Silêncio virtual, Participação, Presença, Controle e Iteração).

Oliveira (2015) conclui que, é possível notar que o professor tem dificuldade de transpor o conhecimento adquirido sobre a utilização do computador nas suas atividades cotidianas para a prática pedagógica em sala de aula. Destaca também, que um professor aprende colaborativamente a partir de um contato com outros professores envolvidos no mesmo processo, podendo garantir, durante as ações pedagógicas, uma comunicação onde seja estabelecida uma troca de conhecimentos teóricos e práticos. Desta forma, valorizando outras estratégias de formação, será possível consolidar um perfil de professor mais aberto para o seu saber e para o saber do outro, considerando que a sua formação está diretamente ligada com a troca de conhecimento.

No estudo de Souza (2018) observa-se um estudo documental voltado para dissertações. Buscou compreender qual o impacto do uso do software Geogebra no ensino da trigonometria como ferramenta para melhorar o aprendizado, o trabalho propõe realizar uma revisão integrativa das dissertações de mestrado, do Mestrado Profissional em Matemática em Rede Nacional (PROFMAT), desenvolvidas nos últimos cinco anos.

Para isso, foi proposta uma pesquisa no banco de dados do PROFMAT com o uso das palavras trigonometria, funções trigonométricas, função seno e radiano, resultando em 134 registros, onde foram selecionados 20 trabalhos.

Tangram - Revista de Educação Matemática, Dourados - MS - v.3 n.1, pp. 74 - 97 (2020) 
Esses trabalhos tiveram os seguintes critérios de seleção adotados: estudos completos disponíveis, o auxílio do Geogebra, trabalhos direcionados ao Ensino Médio regular e arquivos executáveis.

Os dados das 20 dissertações de mestrado foram organizados conforme as seguintes características: autor, ano, local de desenvolvimento do estudo, objetivo, temática de Trigonometria abordada, delineamento, recursos, amostra, contexto, resultados e conclusão.

A maioria dos estudos foi defendida em 2013 (30,0\%), seguido de 2014 (25,0\%) e 2015 (20,0\%). O estado com maior número de produções foi o da Bahia $(15,0 \%)$. Os objetivos das dissertações foram diversificados, englobando atividades presenciais com professores e/ou alunos ou apenas a apresentação didática de determinados recursos, a partir do uso do Geogebra.

De maneira geral, a temática mais frequente nas dissertações, no contexto da Trigonometria, foi funções trigonométricas $(29,0 \%)$, seguido de ciclo trigonométrico $(14,0 \%)$. Os assuntos mais diferenciados foram: radiano (3,0\%) e Função Trigonométrica de Euler $(3,0 \%)$.

A maioria dos estudos teve um delineamento metodológico $(45,0 \%)$, a partir do desenvolvimento de materiais didáticos para auxílio teórico e/ou prático no ensino do conteúdo abordado com o uso do Geogebra. Dentre as dissertações com objetivo exploratório, destacaram-se: pesquisa-ação (15,0\%), estudo comparativo-descritivo $(10,0 \%)$, estudo observacional $(10,0 \%)$ e quase experimental do tipo pré e pós-teste $(10,0 \%)$.

Souza (2018) conclui que os estudos apresentaram diferentes metodologias de desenvolvimento e os resultados apresentados foram variados. O Geogebra, de forma geral, mostrou-se importante ferramenta para auxílio à interpretação de exercícios de trigonometria por alunos do Ensino Médio, com desempenhos satisfatórios em atividades e avaliação positiva por parte dos alunos e professores. As pesquisas apontaram, ainda, um problema referente ao domínio e disposição dos professores do Ensino Médio para a utilização de tecnologias educacionais, especialmente com foco no Geogebra. Os professores, em sua totalidade, reconhecem a importância da implementação de Metodologias Ativas no ensino. A maioria conhece tecnologias educacionais para o ensino da matemática, com foco na trigonometria, incluindo o Geogebra. Entretanto, apenas uma pequena parcela utilizou ou relatou pretender aplicar em sala de aula. Dentre os que utilizaram, foram apontadas

Tangram - Revista de Educação Matemática, Dourados - MS - v.3 n.1, pp. 74 - 97 (2020) 
dificuldades pessoais no manuseio do software, conforme nível de domínio em informática, e relutância em novas administrações no ensino de trigonometria no Ensino Médio. De acordo com o autor, o Geogebra é uma ferramenta educacional que possibilita o aprendizado dos alunos, por mecanismos de caráter criativo e construtivo, minimizando suas dificuldades, aumentando o interesse e a motivação dos mesmos, ampliando suas possibilidades de compreensão dos conceitos inerentes a trigonometria.

\section{Considerações finais}

O presente estudo objetivou apresentar, a partir de um levantamento no Banco de Dissertações e Teses da CAPES, o mapeamento de pesquisas desenvolvidas em Metrados Profissionais, que investigaram o uso de Metodologias Ativas nos processos de ensino e de aprendizagem da Matemática.

Os dados analisados indicam uma pluralidade de estratégias, públicos e conceitos matemáticos envolvidos na implementação de Metodologias Ativas atreladas ao desenvolvimento de pesquisas no âmbito dos Mestrados Profissionais.

Além disso, os dados possibilitou identificar tendências, contextos e práticas envolvendo Metodologias Ativas nos processos de ensino e de aprendizagem da matemática.

Em relação às tendências, observou-se a utilização das seguintes estratégias no rol das Metodologias Ativas: Aprendizagem Baseada em Projetos; Ensino Híbrido; Jogos; Sala de Aula Invertida; Instrução por Pares (Peer Instruction); Aprendizagem Baseada em Times (Team Based Learning) e o uso de Tecnologia educacional. Na perspectiva do Ensino Hibrido, observamos a presença de outras estratégias, como a Gamificação.

Se considerarmos os contextos em que as pesquisas foram desenvolvidas, observase uma predominância de estudos envolvendo alunos de diferentes segmentos, a saber: anos iniciais do Ensino Fundamental, anos finais do Ensino Fundamental, Ensino Médio, Ensino Médio Integrado ao Ensino Técnico e Ensino Superior. Pelo fato os pesquisadores serem, em sua maioria, professores de matemática, observa-se uma ausência de estudos voltados para a Educação Infantil.

Cabe ressaltar, ainda, que há estudos como o de Rech (2016) que focalizou a formação inicial de professores de matemática e a de Oliveira (2015) que se voltou para a formação continuada.

Tangram - Revista de Educação Matemática, Dourados - MS - v.3 n.1, pp. 74 - 97 (2020) 
Ao focalizarmos as práticas decorrentes da implementação das Metodologias Ativas investigadas nos estudos, podemos observar a atuação dos professores como mediadores dos processos de ensino e de aprendizagem da matemática, além da superação do modelo de aula tradicionalmente considerado nas aulas de matemática. Observa-se a valorização da utilização de diferentes plataformas de ensino (Moodle e Class Room); o uso de aplicativos, softwares e linguagens de programação (Socrative, Geogebra e Scratch); além do reconhecimento do smartphones como um aliado nas aulas de matemática.

É importante sinalizar que, uma das dificuldades na realização da tipologia de estudo elegida para o presente artigo, refere-se à ausência de informações relevantes bem como um detalhamento dos procedimentos metodológicos adotados nas pesquisas. Tal deficiência fica latente em dissertações defendidas no âmbito do Mestrado Profissional em Matemática em Rede Nacional (PROFMAT).

Consideramos relevante a continuidade e ampliação do estudo aqui apresentado, analisando as pesquisas vinculadas a Mestrados Acadêmicos e Doutorados (etapa futura) com vistas a possibilitar um olhar mais amplo para a produção brasileira em torno das Metodologias Ativas nos processos de ensino e de aprendizagem da matemática.

\section{Referências}

Almeida, B. L. C. (2017) Possibilidades e Limites de uma Intervenção Pedagógica Pautada na Metodologia da Sala de Aula Invertida para os Anos Finais do Ensino Fundamental. 137 f. Dissertação (Mestrado Profissional em Matemática em Rede Nacional) Universidade Tecnológica Federal do Paraná, Rio de Janeiro.

Ausubel, d. P. (1982)A Aprendizagem Significativa: a teoria de David Ausubel. São Paulo: Moraes.

Brasil. (2017)Ministério da Educação. Base Nacional Comum Curricular. Versão Final. Brasília, DF.

Christensen, C.; Horn, M.; Staker, H.(2013) Ensino Híbrido: Uma inovação Disruptiva? Uma Introdução à Teoria dos Híbridos. Clayton Christensen Institute. Disponível em: $<$ https://www.pucpr.br/wp-content/uploads/2017/10/ensino-hibrido_uma-inovacaodisruptiva.pdf $>$ acesso em 01 de novembro de 2019.

Fiorentini, D.; Passos, C. L. B.; Lima, R. C. R. (Org.).(2016) Mapeamento da pesquisa acadêmica brasileira sobre o professor que ensina matemática: período 2001 - 2012. Campinas, SP: FE/UNICAMP. E-book. Disponível em:

Tangram - Revista de Educação Matemática, Dourados - MS - v.3 n.1, pp. 74 - 97 (2020) 
$<$ https://www.fe.unicamp.br/pffe/pagina_basica/58/e-book-mapeamento-pesquisapem.pdf $>$

Gaeta, M. C. D. (2007) Formação Docente para o Ensino Superior: Uma Inovação em Cursos de Lato Sensu. 213 f. (Programa de Pós-graduação em Educação) - Pontifícia Universidade Católica de São Paulo, São Paulo.

Gomes, R. P. Uma Proposta do Uso De Metodologias Ativas com Auxílio do Software Socrative no Ensino de Matemática. 2018. 97 f. Dissertação (Mestrado Profissional em Matemática em Rede Nacional) - Universidade do Recôncavo da Bahia, Rio de Janeiro.

Matos, V. C. (2018) Sala de Aula Invertida: Uma Proposta de Ensino e Aprendizagem em Matemática. 145 f. Dissertação (Mestrado Profissional em Matemática em Rede Nacional) - Universidade de Brasília, Rio de Janeiro.

Morán, José. (2015) Mudando a educação com metodologias ativas. Coleção Mídias Contemporâneas. Convergências Midiáticas, Educação e Cidadania: aproximações jovens, v. 2, p. 15-33.

Moran, J. (2018) Metodologias Ativas para uma Aprendizagem mais profunda. In: BACICH, L.; MORAN, J. (Org.). Metodologias Ativas para uma Educação Inovadora: Uma Abordagem Teórico-Prática. Porto Alegre: Penso.

Moreira, R. C. (2018) Ensino da Matemática na Perspectiva das Metodologias Ativas: Um Estudo Sobre a "Sala de Aula Invertida". 60 f. Dissertação (Mestrado Profissional em Matemática em Rede Nacional) - Universidade Federal do Amazonas, Rio de Janeiro.

Oliveira, A. L. (2015) Aprendizagem Colaborativa em Ambiente Virtual de Aprendizagem: A Pesquisa do Professor da Educação Básica. 2015. 122 f. Dissertação (Mestrado Profissional em Formação de Professores) - Universidade Estadual da Paraíba.

Paiva, T. Y. (2016) Aprendizagem Ativa e Colaborativa: Uma Proposta de Uso de Metodologias Ativas no Ensino da Matemática. 55 f. Dissertação (Mestrado Profissional em Matemática em Rede Nacional Instituição de Ensino) - Universidade de Brasília, Rio de Janeiro.

Passos, P. P. S. (2016) Metodologias Ativas e Tecnologia: Uma Proposta de Aula Sobre Tópicos Contextualizados de Função Quadrática Com o Auxílio do Programa Socrative. 85 f. Dissertação (Mestrado Profissional em Matemática em Rede Nacional) - Universidade Federal do Estado do Rio de Janeiro, Rio de Janeiro.

Queiroz, V. S. (2018) Contribuições da Linguagem Scratch Para o Ensino da Geometria. 150 f. Dissertação (Mestrado Profissional em Matemática em Rede Nacional Instituição de Ensino) - Instituto de Educação, Ciência e Tecnologia de São Paulo, Rio de Janeiro.

Rech, G. A. (2016) Metodologias Ativas Peer Instruction e Team Based Learning na Formação Inicial de Professores de Matemática. 175 f. Dissertação (Mestrado

Tangram - Revista de Educação Matemática, Dourados - MS - v.3 n.1, pp. 74 - 97 (2020) 
Profissional em Ensino de Ciências Exatas) - Fundação Vale do Taquari de Educação e Desenvolvimento Social - FUVATES.

Sanches, M. N. (2018) Metodologias Ativas e as Tecnologias Digitais da Informação e Comunicação (TDICs): Uma proposta de intervenção na aprendizagem com o auxílio do programa Socrative. 119 f. Dissertação (Mestrado Profissional em Matemática em Rede Nacional) - Universidade Federal do Recôncavo da Bahia, Rio de Janeiro.

Santos, W. P. (2018) Uma Proposta Lúdica Sobre o Summaê No IFG - Câmpus Luziânia. 51 f. Dissertação (Mestrado Profissional em Matemática em Rede Nacional) Universidade Federal do Goiás, Rio de Janeiro.

Schmitt, C. (2018) A Integração das TDICs à Educação Matemática: Um Estudo Sobre o Uso de Ferramentas Digitais e Metodologias Ativas No Ensino e Aprendizagem De Matemática. 196 f. Dissertação (Mestrado Profissional em Matemática em Rede Nacional) - Instituto Federal de Educação, Ciência e Tecnologia De São Paulo, Rio de Janeiro.

Silva, D. F. (2017) O Jogo como Recurso Pedagógico de Ensino: Uma Proposta Para os Números Relativos. 139 f. Dissertação (Mestrado Profissional em Projetos Educacionais de Ciências) - Escola de Engenharia de Lorena, Lorena.

Silva, E. J. (2016) Metodologias Ativas e Tecnologia: Uma Proposta de Aula Sobre Tópicos Contextualizados de Função Afim Com o Auxílio do Programa Socrative. $83 \mathrm{f}$. Dissertação (Mestrado Profissional em Matemática em Rede Nacional) - Universidade Federal do Estado do Rio de Janeiro, Rio de Janeiro.

Sousa, F. D. R. B. (2018) Software Geogebra no Ensino da Trigonometria: Proposta Metodológica e Revisão da Literatura a Partir das Produções Discentes nas Dissertações do PROFMAT. 64 f. Dissertação (Mestrado Profissional em Matemática em Rede Nacional) - Universidade Federal do Maranhão, Rio de Janeiro.

Enviado: 01/11/2019

Aceito: 05/03/2020

Tangram - Revista de Educação Matemática, Dourados - MS - v.3 n.1, pp. 74 - 97 (2020) 